\title{
SISTEMA DE INDICADORES DE
} DESENVOLVIMENTO MUNICIPAL SUSTENTÁVEL: UMA ANÁLISE COMPARATIVA MUNICIPAL INDICATORS SYSTEM SUSTAINABLE DEVELOPMENT: A COMPARATIVE

\author{
ANAL YSIS \\ Anderson Saccol Ferreira ${ }^{1}$ \\ Simone Sehnem ${ }^{1}$ \\ Rógis Juarez Bernardy ${ }^{1}$
}

Recebido em: 23/07/ 2015 Aceito em: 02/12/2015

anderson.ferreira@unoesc.edu.br
Resumo: O artigo analisa os indicadores do desenvolvimento sustentável dos municípios de Chapecó, Joaçaba, Porto União e Mafra, os quais preconizaram a expansão urbana e territorial do Oeste meio Oeste e parte da região Norte Catarinense durante o século XX. Dessa forma, o objetivo da análise é identificar as similaridades e discrepâncias do desenvolvimento municipal sustentável de cada município, propondo caminhos alternativos para melhorar esses índices, conforme os conceitos de Sachs (1997). O trabalho está norteado por uma análise comparativa dos dados, considerando os indicadores de 2012 e 2014, através de uma pesquisa com abordagem documental. A partir dessa análise, identificou e demonstrou os pontos com mais deficiência, mas ao mesmo tempo imprescindíveis para elevar os índices da sustentabilidade dos municípios em termos socioculturais, econômicos, ambientais e político-institucionais.

Palavras-chave: Sustentabilidade. Desenvolvimento Municipal. Indicadores de Sustentabilidade.

Abstract: The article analyzes the indicators of sustainable development in the municipalities of Chapeco, Joaçaba, Port Union and Mafra, which developed the urban and territorial expansion of the West and North of the Santa Catarina region during the twentieth century. Thus, the objective of the analysis is to identify the similarities and differences of municipal sustainable development of each municipality, proposing alternative ways to improve these indexes, through the concepts Sachs (1997). The work is guided by a comparative analysis of data considering the indicators in 2012 and 2014 , through a survey of documentary approach. From this analysis, identified and demonstrated the points with disabilities, but at the same time essential to raise the indices of sustainability of municipalities in socio-cultural terms, economic, environmental and political

Keywords: Sustainability . Municipal development. Sustainability indicators .

\footnotetext{
${ }^{1}$ Universidade do Oeste de Santa Catarina - UNOESC - Joaçaba - Santa Catarina - Brasil.
} 


\section{INTRODUÇÃO}

Este artigo analisa os indicadores do desenvolvimento sustentável dos municípios de Chapecó, Joaçaba, Porto União e Mafra, os quais preconizaram a expansão urbana e territorial do Oeste, Meio Oeste e parte do Norte Catarinense meados século XX.

Durante a década de 30 , tal crescimento foi impulsionado pela extração da madeira e da erva-mate, sendo que, após os anos 40 , houve um impulso dos setores frigorífico e agroindustrial, os quais ainda possuem grande representatividade econômica na região.

Essa análise vai ao encontro dos fatos históricos relacionados à colonização de parte do estado de Santa Catarina, visto que a região estudada teve grande influência na expansão territorial urbana. Salienta-se que, até hoje, esses municípios buscam incessantemente aumentar seus índices de sustentabilidade, o que motivou a pergunta dessa pesquisa: Qual é o comportamento dos indicadores de desenvolvimento sustentável dos municípios de Chapecó, Joaçaba, Porto União e Mafra?

Dessa forma, o objetivo da análise é identificar as similaridades e discrepâncias do desenvolvimento municipal sustentável de cada município, propondo caminhos alternativos para melhorar esses índices, conforme os conceitos de Sachs (1997).

O procedimento metodológico adotado consistiu em analisar o desempenho desses municípios no Índice de Desenvolvimento Municipal Sustentável (IDMS), comparando os resultados desse indicador entre os anos de 2012 e 2014 através de uma abordagem documental dos indicadores, propondo alternativas para elevar seus índices de desempenho sustentável.

Considerando os conceitos de Sachs (1997), adotou-se essa perspectiva com o intuito de que os dados levantados pudessem apontar caminhos para elevar os indicadores de sustentabilidade na dimensão sociocultural, econômica, ambiental e político-institucional.

Sendo assim, o trabalho estrutura-se na contextualização do referencial teórico que subsidia a pesquisa, bem como, no levantamento de dados acerca dos índices de desenvolvimento sustentável e de suas subdivisões, buscando subsídios para propor caminhos e elevar os índices de sustentabilidade da região.

\section{O DESENVOLVIMENTO SUSTENTÁVEL}

O século $X X$ foi marcado por diversas transformações no cenário nacional, principalmente no que diz respeito à expansão urbana. Nas regiões Oeste, meio Oeste e norte de Santa Catarina, esse fenômeno foi mais forte a partir dos anos 30. Nesse período, a economia regional girava em torno da extração da madeira, erva mate e de pequenas indústrias que foram se instalando nos povoados. Outro importante elemento promotor desenvolvimento foi a construção da estrada de ferro, que ligava São Paulo ao Rio Grande do Sul e por onde escoava grande parte da produção. (BELLANI, 1990).

Os municípios de Chapecó, Cruzeiro (atual Joaçaba), Porto União e Mafra, surgiram para representar respectivamente as regiões Oeste, meio Oeste e Norte de Santa Catarina, impulsionando 
a colonização e a organização política e promovendo o desenvolvimento econômico desses territórios.

Todo o século XX foi marcado pela intensa urbanização, sendo que, na década 40 deramse início as atividades agroindustriais e frigoríficas, tornando esses municípios a adquirirem características mais urbanas que rurais. A expansão territorial e o crescimento populacional desencadearam inúmeros problemas, como a falta de infraestrutura, de condições inadequadas de moradia, dificuldades de acesso a serviços de saneamento e transporte coletivo.

Diante desses problemas, o novo milênio surgiu com o desafio de se pensar a cidade como um local menos conflituoso, onde as relações entre o sujeito e seu meio fossem menos destrutivas. Nesse cenário o desenvolvimento sustentável passa ser uma consequência do desenvolvimento social, econômico e ambiental.

Hoje, a busca pela aplicabilidade do desenvolvimento sustentável é nítida, em edificações e empresas. Porém, nos municípios é extremamente complexa, principalmente se levarmos em conta os conceitos social, cultural, ambiental e econômico da sustentabilidade.

Sachs (1993) descreve que a sustentabilidade deve ter uma visão acerca dos problemas sociais e não pode ser focada apenas na gestão dos recursos naturais, em um pensamento mais profundo acerca as mudanças do modo em que a civilização atua.

Nesse contexto, ele apresenta cinco dimensões do ecodesenvolvimento que podem ser planejadas quando se pensa em sustentabilidade urbana.

- Dimensão Social: perspectiva voltada para a construção de uma sociedade com maior equidade na distribuição dos recursos, objetivando a redução das diferenças entre ricos e pobres;

- Dimensão econômica: preocupa-se com o gerenciamento mais efetivo e eficiente dos investimentos públicos e privados;

- Dimensão ecológica: propõe a exploração consciente e responsável dos recursos naturais atrelada ao desenvolvimento de tecnologias que reduzam os impactos das ações humanas ao meio ambiente. A criação de fontes de energia renováveis e a prática da reciclagem estão entre as ações possíveis de serem pensadas nessa dimensão;

- Dimensão espacial ou territorial: preocupa-se com a distribuição espacial das áreas urbanas, considerando o equilíbrio entre os assentamentos urbanos e as atividades econômicas;

- Dimensão cultural: propõe-se a pensar o desenvolvimento urbano em consonância com as características culturais da região e que possa traduzir os conceitos do ecodesenvolvimento (Sachs, 1997).

Mais recentemente, Sachs (1997) passou a considerar a dimensões política nacional, política internacional e a dimensão ecológica.

Na mesma perspectiva, Almeida (2000, p. 18) descreve que "definições variam conforme os objetivos dos agentes de desenvolvimento", isto é, as definições podem tornar-se genéricas e esbarrarem em uma definição ambígua de desenvolvimento sustentável.

Sachs (2004, p. 95) afirma que "o desenvolvimento sustentável pode ser pensado a partir da perspectiva social ou ambiental". As diferentes maneiras de perceber a sustentabilidade consideram que políticas de desenvolvimento ora estejam focadas nos aspectos sociais e ora nos aspectos 
ambientais, mas sempre dialogando com a dimensão econômica (Sachs 2004). Nesse sentido, a esfera ambiental passa a ser considerada como capital e necessita ser preservada, contabilizado como um custo de ativos sendo medido por indicadores e índices de sustentabilidade.

Para Sachs (2007, p. 296), "alcançar um desenvolvimento genuinamente sustentável e sadio, os critérios de sustentabilidades precisam ser satisfeitos em todas as dimensões pertinentes do desenvolvimento". É claro, não há como desenvolver sustentabilidade sem que todas as dimensões estejam em equilíbrio.

Na ótica de Sachs (2007, p. 297) "esses critérios devem ser como pontos de referência de indicadores mais da direção desejada dos processos do que um estado final". Ressalta ainda, que a proposta deve partir da premissa sendo o social como o cume da pirâmide da sustentabilidade, o ambiental como uma restrição e o econômico comum papel instrumental (SACHS, 2007).

Nesse sentido, o economista afirma que "a sustentabilidade visa alcançar um patamar razoável de homogeneidade social com distribuições de renda justas e a promoção de igualdade no acesso aos recursos e serviços sociais”. (Sachs, 2007, p. 85) É importante salientar que as práticas de sustentabilidade adotadas pelos municípios tem priorizado o aspecto econômico, em detrimento das dimensões social, ambiental e cultural.

Para Sachs, pensar em sustentabilidade envolve refletir sobre a formação dos sujeitos promotores do desenvolvimento sustentável, considerando que "a educação é essencial para o desenvolvimento, pelo valor intrínseco, na medida em que contribui para o despertar cultural, a conscientização, a compreensão do direitos humanos". (SACHS, 2007, p. 86) Ao mesmo tempo, ele destaca que "a educação também tem valor instrumental com respeito à empregabilidade." (SACHS, 2004, p. 82).

Na ótica da Organização das Nações Unidas para a Educação, a Ciência e a Cultura (UNESCO, 2014, p. 58), "qualidade na educação é uma categoria central no paradigma da educação sustentável". A educação pode ser um dos pontos fundamentais para elevar os índices da sustentabilidade, sendo uma ferramenta extremamente importante para combater a pobreza e a desigualdade social, podendo, inclusive, melhorar as condições de saúde e bem estar social.

Portanto, a literatura acerca dos conceitos de Sachs (1993), demonstra, na prática, que a premissa educacional pode auxiliar na criação das bases para o desenvolvimento sustentável, ou seja, suas definições acerca das dimensões cultural, social, econômica, ambiental e territorial, sustentam a pesquisa acerca dos índices de desenvolvimento sustentável com as ações praticadas pelos municípios que podemos demostrar no decorre da pesquisa.

Ainda que o investimento na formação dos indivíduos seja imprescindível para se pensar a construção da sustentabilidade, não se pode esperar que a educação, sozinha, promova o desenvolvimento sustentável de uma região. Nesse sentido, a promoção de políticas públicas é fundamental para que ocorram mudanças que melhorem efetivamente as condições de vida nas cidades. 


\section{PROCEDIMENTOS METODOLÓGICOS}

A pesquisa utilizou o processo metodológico documental que, segundo Cellard (2008, p. 298) "[...] vale-se de documentos originais, que ainda não receberam tratamento analítico por nenhum autor". Helder (2006, p. 1-2) descreve que "esse método de coleta de dados que elimina, ao menos em parte, a eventualidade de qualquer influência do pesquisador", isto é, extingue a intervenção do pesquisador no conjunto de interações ou acontecimentos, anulando a possibilidade de reação do sujeito à operação de medida.

Pimentel (2001, p. 179) descreve que o método documental "contribui para utilização da análise documental em pesquisa esse texto apresenta o processo de uma investigação", ou seja, como uma técnica exploratória indicando problemas que podem no futuro ser explorados através de outros métodos.

Assim, analisamos os Índices de Desenvolvimento Municipal Sustentável (IDMS) dos municípios de Chapecó, Joaçaba, Porto União e Mafra visando comparar os avanços desses municípios em termos de desenvolvimento sustentável, comparamos o desempenho que tiveram no IDMS nos anos de 2012 e de 2014, empregando como referência os conceitos de Sachs (1997) nos âmbitos sociocultural, econômico, ambiental e político-institucional e suas subdivisões.

Os dados foram coletados seguindo os seguintes critérios avaliativos: no primeiro momento foram analisados os indicadores das dimensões sociocultural, político-institucional, econômico e ambiental; em um segundo momento, foi analisado as subdivisões relatando seus indicadores; e num terceiro momento as variáveis das subdivisões.

Os dados foram tabulados considerando os seguintes parâmetros: indicadores menores que $50,0 \%$ foram classificados como baixos; desempenho maior ou igual a $50,0 \%$ e menor que $62,5 \%$ considerado médio baixo; para resultados maiores ou iguais a $62,5 \%$ e menores que $75,0 \%$, categorizou-se como médio; índices maiores ou iguais a $75,0 \%$ e menores do que $87,5 \%$ foram classificados de médio alto; quando o desempenho foi igual ou superior a $87,5 \%$, considerou-se como alto.

A partir dessa classificação dos dados foi possível organizar as informações e gerar gráficos demonstrativos que possibilitou a comparação dos índices.

Através de indicadores de sustentabilidade foi possível entender os pontos mais relevantes que possibilitam melhorar a classificação na escala de desenvolvimento sustentável do estado de Santa Catarina.

\section{COMPORTAMENTO DOS INDICADORES DE DESENVOLVIMENTO SUSTENTÁVEL}

As cidades que praticam ações para melhorar a qualidade de vida de seus habitantes, tanto na esfera econômica, quanto social, ambiental e cultural, promovem o desenvolvimento sustentável. Várias cidades no estado de Santa Catarina adotam essas práticas, no entanto, nenhuma delas promove práticas $100 \%$ sustentáveis. 
Dessa forma, optamos por realizar uma análise centrada em quatro dimensões do desenvolvimento municipal sustentável, quais sejam: a sociocultural, a econômica, a ambiental e a política. A escolha dessa abordagem está relacionada à importância desses aspectos para a transformação da realidade dos municípios e para a promoção do bem-estar social, através da identificação e análise de processos que possam promover o desenvolvimento regional de forma sustentável.

$\mathrm{Na}$ primeira etapa da pesquisa, analisamos a classificação geral dos municípios estudados no IDMS do estado de Santa Catarina, nos anos de 2012 e 2014.

Referente ao ano de 2012 foi possível identificar a seguinte realidade: o município de Mafra ocupava o $14^{\circ}$ lugar na classificação, seguida de Joaçaba em $26^{\circ}$, Chapecó em $35^{\circ}$ e Porto União em $209^{\circ}$.

Com relação aos dados levantados sobre o ano de 2014, foi possível perceber diferenças consideráveis no desempenho dos municípios. Joaçaba passou a ocupar a $11^{\circ}$, Mafra, a $27^{\circ}$. Chapecó, a $57^{\circ}$ e Porto União, a $77^{\circ}$ posição no ranking de desenvolvimento sustentável. Nota-se que o município de Porto União destacou-se pela ascensão de 132 posições no ranking e Joaçaba subiu 15 posições em relação a 2012. Enquanto isso, os municípios de Chapecó e Mafra apresentaram um desempenho inferior a 2012, já que regrediram 22 e 3 posições, respectivamente.

A partir desses dados, buscou-se identificar as deficiências e potencialidades de cada município, as quais justificassem a queda ou elevação de seu desempenho no índice. Para tanto, adotamos as dimensões de sustentabilidade e suas variáveis como base para a reflexão.

Inicialmente, analisamos a dimensão sociocultural, a qual está relacionada com importantes subdivisões como saúde, educação, cultura e habitação. Sachs (1997, p. 86) "considera ser esta a dimensão mais difícil de ser concretizada, pois está relacionada ao caminho da modernização sem o rompimento da identidade cultural dentro de contextos espaciais específicos".

Nessa perspectiva, a comparação dos índices do IDMS dos anos de 2012 e 2014 demonstra a evolução dos municípios de Joaçaba, Porto União e Chapecó, que melhoraram seu desempenho no índice positivamente em 13,2\%, 10,7\% e 2,9\%, respectivamente. Enquanto isso, Mafra apresentou uma involução de -2,9\% em sua classificação, conforme de mostra o gráfico 1.

Estudos do CEPE [ISSN 1982-6729]. Santa Cruz do Sul, n. 42, p. 204-218, jul./dez. 2015. https://online.unisc.br/seer/index.php/cepe/index 


\section{Gráfico 1: Índices socioculturais extraídos do IDMS}

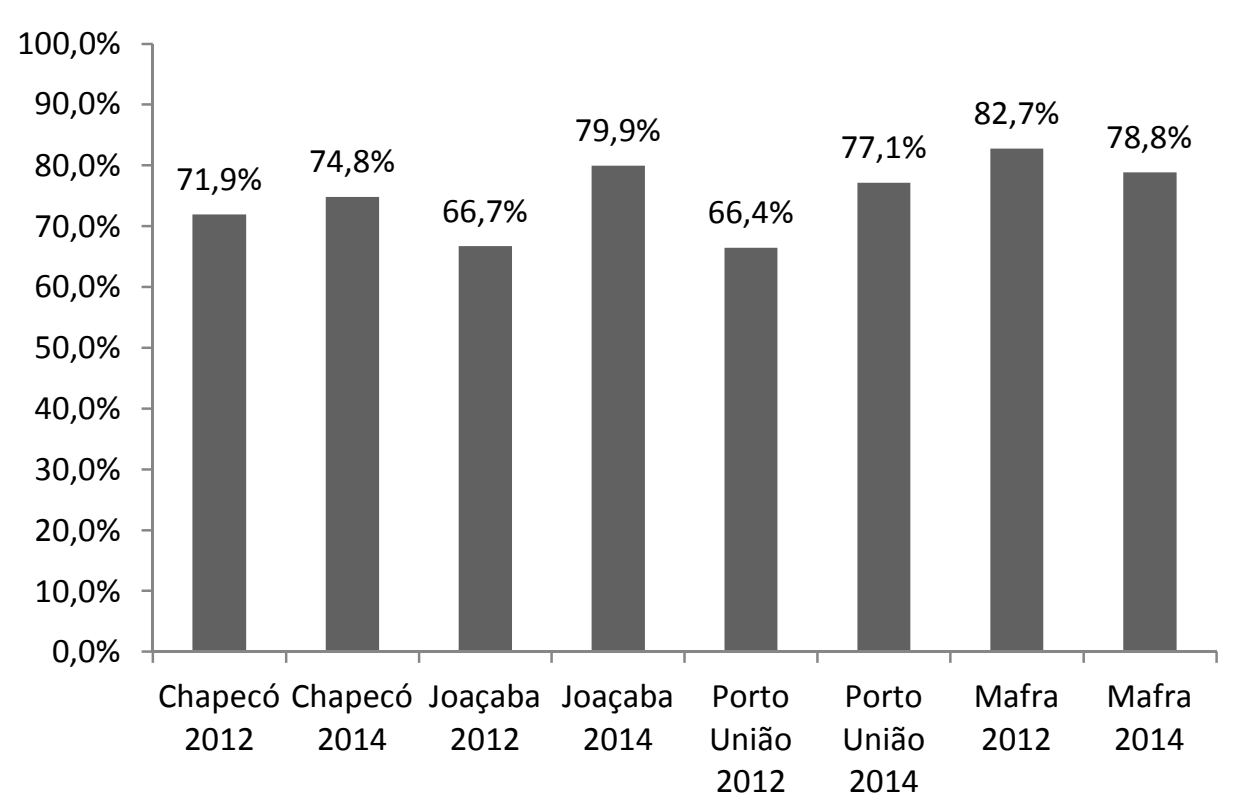

Fonte: Fonte: Cálculos realizados a partir de dados do IDMS (2012 e 2014).

Diante disso, torna-se importante uma análise mais detalhada dos índices socioculturais. Sachs (1997, p. 88) destaca que "a sustentabilidade sociocultural refere-se a um processo de desenvolvimento que leva a um crescimento estável". Isso ocorre, pois essa dimensão do desenvolvimento sustentável ancora-se no princípio da igualdade dos direitos, na promoção da dignidade humana e na distribuição de bens e renda, ou seja, a dimensão sociocultural através do IDMS avalia os indicadores acerca educação, saúde, cultura e habitação.

A dimensão educacional demonstra os indicadores de qualidade da educação e o acesso desse serviço à população em idade escolar, o município de Chapecó teve um aumento de 8,7\%, seguida por Porto União, com 18,5\% e Joaçaba, com 30,3\%. Mafra, por sua vez, teve um decréscimo de $-7,4 \%$ nesse critério.

Com relação à saúde, que considera os índices de mortalidade nos fatores de risco e proteção através do percentual de nascidos vivos com baixo peso no último triênio, cobertura da atenção básica, morbidade e recursos na saúde acerca da taxa de anos potenciais de vida perdidos por óbito registrado, Chapecó teve um decréscimo de $-2,5 \%$, Joaçaba de $-4,2 \%$ e Mafra de $-2,8 \%$. Nesse quesito, apenas Porto União demonstrou elevação no índice, que correspondeu a 8,9\%.

A dimensão cultural foi outro aspecto analisado e envolve a estrutura de gestão para promoção da cultura, iniciativas da sociedade, infraestrutura cultural e recursos investidos na cultura. Nesse item, Chapecó apresentou um decréscimo de $-7,7 \%$ em seu desempenho, seguida por Porto 
União, com decréscimo de $-8,1 \%$ e Mafra, com involução de $-12,2 \%$. O município de Joaçaba, por sua vez, apresentou um avanço de 10,1\% nesse critério.

No tocante à habitação, que avalia a estrutura de gestão para políticas habitacionais e a qualidade habitacional, identificou-se que nenhum município apresentou desempenho negativo. Joaçaba e Porto União, por sua vez, mantiveram, em 2014, o mesmo patamar apresentado em 2012. Enquanto isso, Chapecó demonstrou um acréscimo de 6,3\% e Mafra de 6,2\%.

Analisando-se os dados do IDMS, identificamos aspectos relevantes e que apontam caminhos para elevar os índices na dimensão sociocultural. Nesse sentido, destaca-se o aumento da nota no Índice de Desenvolvimento da Educação Básica (IDEB) da Rede Pública, a diminuição do percentual de abandono escolar no ensino médio, bem como, a taxa de atendimento escolar das redes públicas e privadas.

O caso de Joaçaba ilustra essa afirmação, em 2012, o município apresentou um índice de 63,9\% (MEC/INEP, 2010) na variável IDEB da Rede Pública, percentual que evoluiu para 90,6\% (MEC/INEP, 2012) em 2014. Em relação ao mesmo período, também foi possível perceber um diminuição do percentual de abandono escolar no ensino médio, que em 2012 foi de 83,1 \% e em 2014, 64,2\%. Paralelamente a isso, houve uma elevação na taxa de atendimento escolar das redes pública e privada de ensino, que passou de $45,5 \%$ para $100 \%$ o que corresponde a avaliação máxima do IDMS.

É importante salientar que o desempenho do município em outras áreas, como saúde, cultura e habitação não interferiram acentuadamente na alteração do IDMS.

Diante dessas informações, percebe-se que houve ações de investimento mais focadas no quesito educação, referenciando o alcance de patamares de homogeneidade social em termos de qualidade de vida e acesso aos recursos de igualdade social.

$\mathrm{Na}$ sequência, a pesquisa voltou-se para a análise da dimensão econômica do desenvolvimento sustentável, a qual compreende os indicadores relacionados ao nível de renda, dinamismo econômico e agregação de valor econômico.

Essa dimensão consiste em analisar a sustentabilidade na esfera que engloba a geração de trabalho e distribuição de renda, bem como, as potencialidades locais, diversificando os setores da atividade econômica. Segundo Sachs (1993, p. 123), "a sustentabilidade econômica é possibilitada por uma alocação e gestão mais eficiente dos recursos e por um fluxo regular do investimento público e privado". Nesse sentido ela possibilita alocação e gestão eficiente dos investimentos.

Ao analisarmos o contexto econômico, levando em consideração os indicadores das dimensões, subdimensões e suas variáveis, obtivemos os resultados comparativos. Através deles, identificamos que o município de Porto União foi o único dentre os quatros municípios analisados que apresentou nível de percentual do crescente econômico com 1\%. Por outro lado, os municípios de Joaçaba, Chapecó e Mafra apresentaram uma involução entre 2012 para 2014 de -0,3\%, -4,8\% e $5,3 \%$, respectivamente. O gráfico 2 apresenta o comparativo dos índices. 
Gráfico 2: Indicadores de economia do IDMS

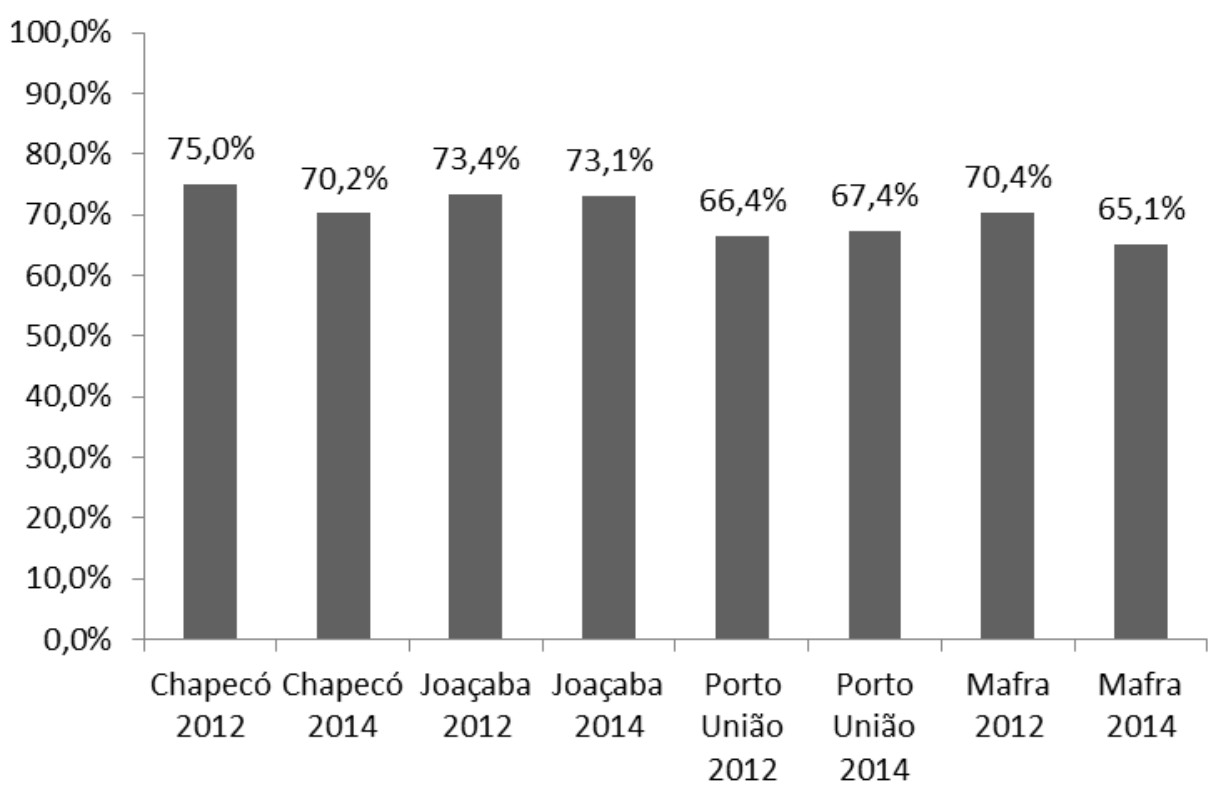

Fonte: Cálculos realizados a partir de dados do IDMS (2012 e 2014).

Nesse sentido, analisamos os indicadores acerca do nível de renda, ou seja, a remuneração média dos trabalhadores formais e o percentual de domicílios em situação de pobreza. Os dados mostram que de 2012 para 2014 no indicador nível de renda o município de Mafra obteve o maior percentual com 3,3\%, seguida de Chapecó com 3,1\%, Joaçaba com 2,4\% e Proto União com 1\%.

Já no indicador dinamismo econômico onde as variáveis designam acerca da evolução da área liberada para construção no último triênio, bem como, na evolução dos empregos formais no último triênio e Produto Interno Bruto (PIB) per capita, os municípios nos mostram um índice decrescente, sendo Mafra com 12,4\%, Joaçaba com 5,6\% e Chapecó com 1,2\%. Já o município de Porto União demonstra índices crescentes de 5,5\%.

O índice agregação de valor econômico onde temos as variáveis acerca da evolução média do valor adicionado no último triênio e a média de crescimento do Imposto Sobre Serviço (ISS) no último triênio, três municípios mostram índices decrescente, Chapecó com 5,2\%, Mafra com 6,9\%, Porto União com 3,6\%, apenas Joaçaba destaca-se com índice crescente de 2,6\%. Nesse sentido, o município que mais se cresceu no indicador econômico em relação ao ano de 2012 para o ano de 2014 foi Porto União, e o que teve maior índice decrescente foi Mafra. Dessa forma, analisamos as eficiências econômicas em termos macro-sociais, não apenas nos critérios de lucratividade considerando os impactos de fluxos monetários existentes entre as empresas o município e a população.

A terceira dimensão analisada refere-se a político-institucional no qual, estão subdivididas em participação social e gestão pública. Essa dimensão visa à participação ativa das pessoas favorecendo o acesso as informações que permitira a melhor compreensão na busca de soluções 
para eventuais problemas, superando as práticas políticas de exclusão e buscando o consenso nas decisões coletivas.

Segundo o relatório de Brundtland (1987, p. 58) "A sustentabilidade política será alcançada, com a democratização da sociedade e a democratização do Estado, a democratização de um sendo condição da do outro", ou seja, a sustentabilidade política só será almejada quando a sociedade desdenhar condições de conduzir suas próprias políticas sempre levando em consideração o exercício da cidadania como instrumento de gestor.

Seguindo essa linha de raciocínio, esta demissão manteve os índices em ascensão em todos os municípios, Joaçaba por sua vez teve o maior percentual de 9,9\% seguido por Mafra com 8,2\%, Porto União com 6\% e Chapecó com 0,3\%. O gráfico 3 demonstra evolução do ano 2012 para 2014.

\section{Gráfico 3: Indicadores político-institucionais do IDMS de 2012 e 2014}

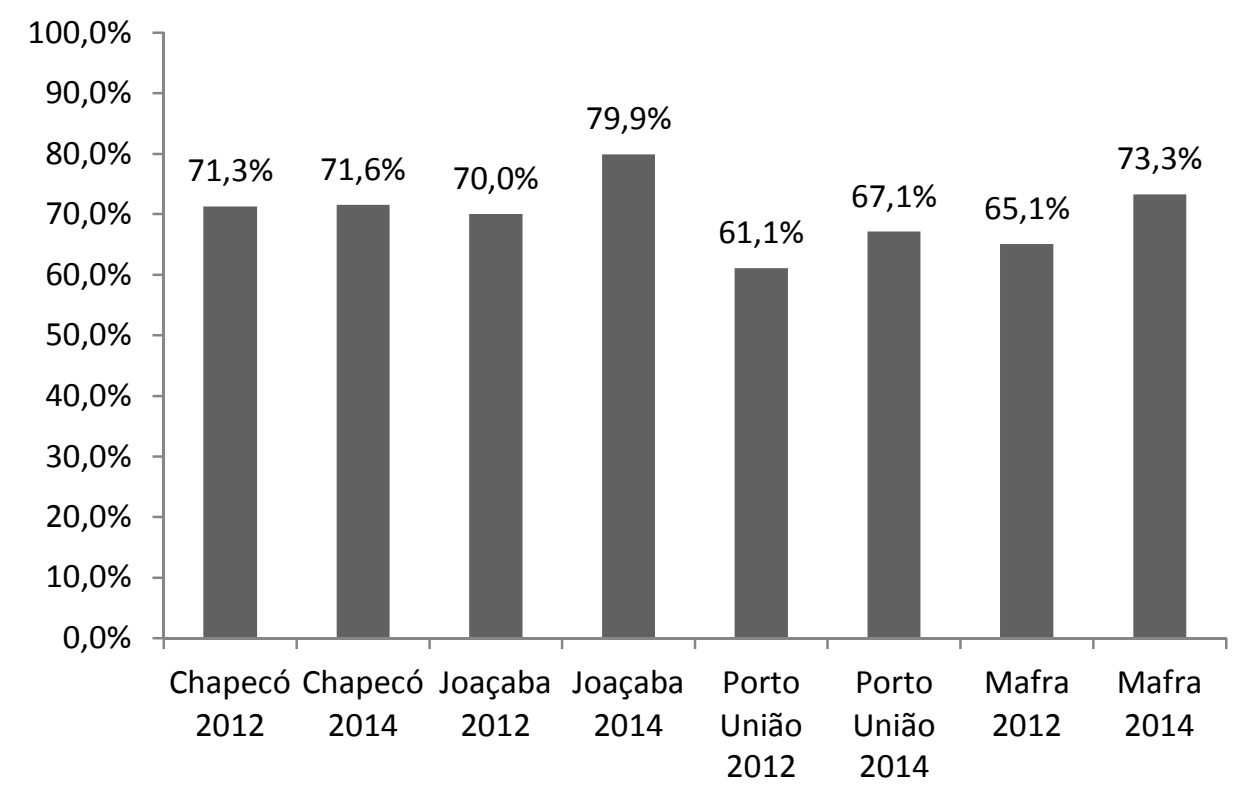

Fonte: Cálculos realizados a partir de dados do IDMS (2012 e 2014).

Ainda sobre a dimensão político-institucional, buscamos analisar a subdimensão das finanças públicas, a qual está relacionada à capacidade de arrecadação e investimento, bem como, com a saúde financeira dos municípios. Nesse indicador, o município de Joaçaba teve um aumento percentual de 13,7\% em seu desempenho, seguido por Chapecó, com 2,2\%, Mafra, com 1,7\% e Porto União com involução de $-0,5 \%$.

Referente à gestão pública, a pesquisa focou-se na capacidade de planejamento, de articulação com o exterior, assim como nos aspectos relacionados à qualidade do quadro funcional e da gestão de pessoas. Nesse indicador, todos os municípios apresentaram desempenho crescente quando comparados os dados de 2012 e 2014: Joaçaba, com evolução de 11,1\%, seguida de Mafra, com 8,6\%, Porto União, com 6\% e Chapecó com 5,7\%.

A subdimensão que avalia a participação social tem como indicadores o índice de participação eleitoral, o capital social acerca da existência de planos de desenvolvimento setoriais e a 
gestão democrática através da existência de plano de cargos e salários existência de plano de capacitação de servidores, bem como, o percentual de mulheres vereadoras. O município que mais progrediu nesse critério foi Mafra, com ascensão de 16,4\%, já Porto União, teve alta de 14,8\% e Joaçaba 3,3\%. Em contraponto, Chapecó teve resultado negativo nesse critério: em 2012, seu desempenho foi de $64 \%$, enquanto em 2014 foi $56,8 \%$, uma queda de $-7,5 \%$ nesse período. Esse decréscimo deu-se pelo baixo percentual de mulheres vereadoras no ano de 2014.

Outro ponto de análise foi à dimensão ambiental da sustentabilidade, a qual se compreende pelas dinâmicas do meio ambiente, considerando o ser humano apenas uma das partes do meio (RATTNER, 1999).

Foladori (2002, p. 623) destaca que, "a sustentabilidade ecológica é a que suscita menos controvérsias, uma vez que se refere a certo equilíbrio e à manutenção dos ecossistemas, conservação e manutenção genética, incluindo, também, a manutenção dos recursos abióticos e a integridade climática". Essa perspectiva parte do princípio de que quanto mais o ser humano modifica a natureza, menor será a sustentabilidade ambiental. Em contraponto, quanto menos interferência, maior a sustentabilidade.

A partir disso, analisamos os indicadores sustentáveis da subdimensão ambiental. A capacidade de cobertura do saneamento básico é um deles e contempla o percentual de domicílios atendidos direta ou indiretamente pelos serviços de coleta de lixo, rede geral de esgoto ou fossa séptica.

Outro importante indicador dessa dimensão é a preservação ambiental, que aborda questões como a depósito de lixo em locais licenciados e a preservação de matas e florestas naturais nas propriedades agrícolas.

A estrutura da gestão ambiental também é um fator de análise quando se pensa em sustentabilidade, considerando a importância da efetividade da estrutura de gestão ambiental e do conselho municipal de meio ambiente.

Ao analisarmos essa dimensão Porto União teve uma grande alteração positiva, enquanto os outros três municípios os percentuais foram mais baixo, conforme demonstra o gráfico.

Estudos do CEPE [ISSN 1982-6729]. Santa Cruz do Sul, n. 42, p.204-218, jul./dez. 2015. https://online.unisc.br/seer/index.php/cepe/index 


\section{Gráfico 4: Indicadores alusivos ao meio ambiente, extraídos através do IDMS}

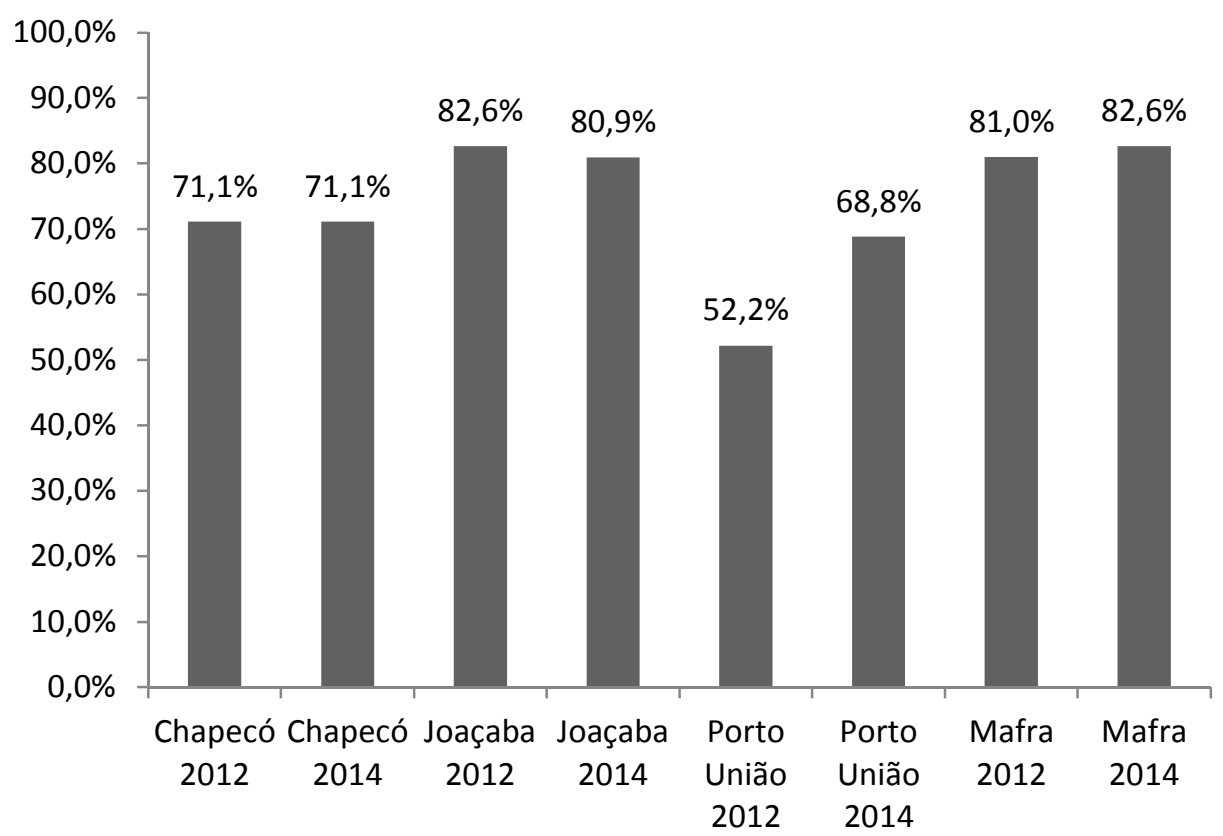

Fonte: Cálculos realizados a partir de dados do IDMS (2012 e 2014).

Enquanto o município de Chapecó manteve seu desempenho estável nesse quesito, Joaçaba apresentou uma involução de $-1,7 \%$ e Mafra uma evolução de 1,6\%. Porto União, por sua vez, destacou-se com um progresso de $16,6 \%$ nesse indicador, o maior índice dentre os quatro municípios analisados

Quanto à estrutura de gestão ambiental, os municípios de Chapecó e Porto União permaneceram estáveis, mantendo o mesmo índice. Joaçaba, por sua vez, apresentou um decréscimo de $5 \%$ e Mafra uma ascensão de 7,5\%.

No indicador preservação ambiental, apenas Porto União obteve uma ascensão expressiva, elevando seu índice de 50\% para 100\%. Os demais municípios mantiveram-se estáveis nesse critério.

Dessa forma, os resultados da pesquisa contribuem para compreender o contexto em que os municípios estão inseridos e a pensar alternativas para melhorar seus índices de sustentabilidade em todas as dimensões, considerando que eles carregam o fardo histórico de alavancar o desenvolvimento regional.

Para a comunidade, esta pesquisa demonstra as áreas que mais recebem investimentos pela administração pública e, consequentemente, as que necessitam de maior atenção dos gestores municipais.

Nesse sentido, a pesquisa demonstrou que a dimensão mais vulnerável é a sociocultural, que envolve aspectos como saúde, educação, cultura e habitação, os quais interferem diretamente na qualidade de vida dos munícipes.

Estudos do CEPE [ISSN 1982-6729]. Santa Cruz do Sul, n. 42, p. 204-218, jul./dez. 2015. https://online.unisc.br/seer/index.php/cepe/index 
É possível identificar algumas implicações desses resultados, sendo que a relação da teoria estudada com o que se verifica na prática é evidente, principalmente quando se pensa a dimensão sociocultural e o seu potencial para promover os patamares razoáveis de hegemonia social. Segundo Sachs (1997), estes patamares só serão alçados quando a distribuição igualitária de renda, a qualidade de vida e o acesso aos recursos sociais, principalmente à educação de qualidade, forem universalizados.

É notável que uma população educada, preocupada com o seu desenvolvimento físico, intelectual e moral, conseguem observar melhor e entender e aplicabilidade do desenvolvimento sustentável. O exemplo de Joaçaba ilustra essa afirmação, pois, dentre os municípios estudados, é o que apresenta o melhor índice na dimensão sociocultural, o que contribui para o seu bom desempenho em outras dimensões.

Os resultados desse estudo apresentam dois aspectos que podem ser considerados inovadores. O primeiro está relacionado ao fato de um município do meio oeste catarinense ter se destacado com $01^{\circ}$ lugar da região no IDMS, devido seu bom desempenho na dimensão sociocultural.

O segundo aspecto refere-se ao desempenho do município de Porto União, que subiu 132 posições no ranking entre 2012 e 2014, demonstrando que as ações voltadas para o desenvolvimento sustentável repercutem em diversos setores da sociedade e transformam a realidade dos municípios.

Ressaltamos ainda, que a sustentabilidade só atingirá seu objetivo quando todas as dimensões se sustentarem, isto é, quando os resultados fazem parte de um processo ou sistema que possa permitir a sua permanência contínua a longo prazo sendo analisados continuamente.

\section{CONSIDERAÇÕES FINAIS}

O desenvolvimento sustentável dos municípios vem sendo debatido constantemente, principalmente no que se refere às práticas desenvolvidas nas esferas social, econômica, cultural e ambiental.

Dessa forma, o objetivo da análise passou a identificar as similaridades e discrepâncias do desenvolvimento municipal sustentável de cada município, propondo caminhos alternativos para melhorar esses indicadores, conforme os conceitos de Sachs (1997), os quais foram confrontados demonstrando as deficiências que podem ser sanadas aumentando os indicadores de desempenho.

O procedimento metodológico adotado procurou analisar o desempenho desses municípios acerca do IDMS comparando os resultados desse indicador entre 2012 e 2014 através de uma abordagem documental, propondo alternativas para elevar seus índices de desempenho sustentável, bem como, algumas práticas citadas na pesquisa que podem ser implementadas ou melhoradas dentro do desenvolvimento sustentável.

Nesse sentido a análise demonstrou que práticas sustentáveis vêm sendo desenvolvidas em contínua permanência, na busca de melhores condições de igualdade nos recursos ambientas e sociais.

Estudos do CEPE [ISSN 1982-6729]. Santa Cruz do Sul, n. 42, p.204-218, jul./dez. 2015. https://online.unisc.br/seer/index.php/cepe/index 
Quanto aos resultados obtidos, ficou constatado que um dos indicadores pode contribuir para elevar os índices esta no âmbito sociocultural principalmente acerca da educação, ou seja, a criação de estratégias que possam dar condições para desenvolver novas práticas educacionais, concentrando ações estratégicas para realizar mudanças necessárias na questão da responsabilidade acerca das metas da sustentabilidade em suas múltiplas dimensões: econômica, social, política e ambiental, indo em direção as premissas dos conceitos de Sachs.

Por fim, a análise demonstrou em quais condições estão os indicadores do desenvolvimento sustentável e quais são as medidas possíveis para elevar seus indicadores, visto que historicamente eles preconizaram o desenvolvimento regional em uma época onde pouco eram as preocupações com o meio social e ambiental. Já que os principais meios de renda estavam focados na extração da madeira e erva mate no inicio do século $\mathrm{XX}$, indo a encontro com práticas de desenvolvimento sustentáveis nas quais são aplicadas continuamente conforme os índices evidenciam na pesquisa.

\section{REFERÊNCIAS}

ALMEIDA, D. L. Agricultura Orgânica: Instrumento para a sustentabilidade dos sistemas de produção e valoração de produtos agropecuários. Seropédica: Embrapa Agrobiologia, dez. 2000. 22p. (Embrapa Agrobiologia. Documentos, 122).

BELLANI, E. M. Santos Marinho e Passos Maia: A política no velho Chapecó (1917 1931). Chapecó: Litoprint Editora, 1990.

BRASIL, Ministério do Planejamento, Orçamento e Gestão. Servidores públicos federais cada vez mais qualificados. Brasília, 2009.

BRUNDTLAND, G. H. Nosso futuro comum: Comissão mundial sobre meio ambiente e desenvolvimento. 2.ed. Rio de Janeiro:Fundação Getúlio Vargas, 1991.

CELLARD, A. A análise documental. In: POUPART, J. et al. A pesquisa qualitativa: enfoques epistemológicos e metodológicos. Petrópolis, Vozes, 2008.

DALY, H. E. Crescimento sustentável? Não, obrigado. In: Ambiente \& sociedade, jul-dez; ano/vol. 7, n. 002. Campinas: Associação nacional de pós-graduação e pesquisa em ambiente e sociedade ANPPAS, 2004. p. 197-201.

FOLADORI, G. Avances y límites de la sustentabilidad social. In: Economia, sociedad y território. vol. III, num. 12, 2002, p. 621-637.

HELDER, R. R. Como fazer análise documental. Porto, Universidade de Algarve, 2006.

IBGE, Instituto Brasileiro de Geografia e Estatística. Série relatórios metodológicos: Produto interno bruto dos municípios. Vol. 29, Rio de Janeiro, 2004. Disponível em:<www.ibge.gov.br> . Acesso: Julho de 2015.

Produto interno bruto dos municípios, 1999-2003. Rio de Janeiro, 2005 Disponível em:<www.ibge.gov.br> . Acesso: Julho de 2015.

IBGE, Instituto Brasileiro de Geografia e Estatística. Perfil dos municípios brasileiros: Pesquisa de informações básicas dos municípios brasileiros 2008 e 2009. Rio de Janeiro, 2010. Disponível em:<www.ibge.gov.br> . Acesso: Julho de 2015.

Pesquisa nacional por amostra de domicílio (PNAD).Rio de Janeiro, 2010. Disponível em: $<w w w . i b g e . g o v . b r>$. Acesso: Julho de 2015. 
Censo demográfico de 2010.Vol. 29, Rio de Janeiro, 2010. Disponível em:<www.ibge.gov.br> . Acesso: Julho de 2015.

Censo demográfico de 2010 - 2013. Rio de Janeiro, 2013. Disponível em:<www.ibge.gov.br>. Acesso: Julho de 2015.

LEFF, E. Saber ambiental: sustentabilidade, racionalidade, complexidade, poder. Petrópolis: Vozes, 2001.

MEC, Ministério da Educação. Perfil dos conselhos municipais da educação 2007. Brasília, 2008. MEC, Ministério da Educação. Nota Técnica: Índice de Desenvolvimento da Educação Básica -ldeb. Brasília, 2010. Disponível em: <www.portal.mec.gov.br > . Acesso: Julho de 2015.

Índice de Desenvolvimento da Educação Básica - IDEB. Brasília, 2010. Disponível em: <www.portal.mec.gov.br > . Acesso: Julho de 2015

PIMENTEL, A. O método da análise documental: Seu uso numa pesquisa histórica.

Cadernos de Pesquisa, n.114, p.179-195, nov., 2001.

RATTNER, H. Sustentabilidade: uma visão humanista. Ambiente e sociedade, jul/dec. 1999, n. 5, p. 233-240.

SACHS, I. Sustentabilidade social e desenvolvimento integral. In: SACHS, Ignacy.

SACHS, I. Desenvolvimento includente sustentável. São Paulo: Garamod, 2004.

SACHS, J. O fim da pobreza: como acabar com a miséria mundial nos próximos vinte anos. São Paulo: Companhia das Letras, 2005. 449 p

SACHS, I. Eco desenvolvimento: crescer sem destruir. São Paulo: Vértice, 1986.

Do crescimento econômico ao ecodesenvolvimento. In: VIEIRA, Paulo Freire; $\overline{R I B E I R O}$, Maurício Andrés; FRANCO, Roberto Messias; CORDEIRO, Renato Caporali (Org.). Desenvolvimento e meio ambiente no Brasil: a contribuição de Ignacy Sachs. Florianópolis: Palotti/APED, 1998.

. Desenvolvimento: includente, sustentável, sustentado. Rio de Janeiro: Garamond, 2004.

SACHS, I. Estratégias de transição para o século XXI. In: BURSZTYN, M. Para Pensar o Desenvolvimento Sustentável. São Paulo: Brasiliense, 1993. p. 29-56.

SIDEMS, Sistema de Indicadores de Desenvolvimento Municipal Sustentável. 2012 e 2014. Disponível em: <indicadores.fecam.org.br> . Acessado em: Julho de 2015.

TOURAINE, A. Crítica da modernidade. Petrópolis: Ed. Vozes, 1994, 423p.

UNESCO, Organização das Nações Unidas para a Educação, a Ciência e a Cultura. Década das Nações Unidas da Educação para o Desenvolvimento Sustentável (2005-2014). Brasília: Unesco. 